\title{
Design with Knowledge-Light in Learning Environments
}

\author{
Imke Wies van Mil, Olga Popovic Larsen, Karina Mose, and Anne Iversen
}

\begin{abstract}
A range of artificial lighting characteristics have been found to influence our visual and cognitive capabilities, mood, motivation and/or (social) behaviourall affecting how we (academically) perform. One such influential characteristic is spatial contrast, or the way light is distributed in space causing a pattern of light and darkness. This study looks at if and how spatial contrast influences pupil behaviour, and specifically their ability to concentrate. We first explored whether variances in pupil noise, physical activity and mood, which have been found to affect concentration, occur when exposed to either a high or a low spatial contrast in their learning environment. Preliminary data from field experiments in a primary school indicates towards decreased noise levels and improved environmental satisfaction when a high spatial contrast condition is present. This implies improved environmental circumstances to concentrate. Further research to confirm this assumption will be undertaken.
\end{abstract}

\section{Introduction}

A significant body of evidence has been accumulated that demonstrates our physical (built) environment influences our ability to act (Gifford, 2007). This has been found particularly true for educational environments, where a range of parameters has been identified that influences our behaviour, wellbeing, and ultimately academic performance. Light is one of such influential parameters (Barrett et al., 2015). For those designing or using educational facilities, it is relevant to understand how lighting conditions may influence our ability to perform curricular

I. W. van Mil (更) · O. Popovic Larsen · K. Mose

The Royal Danish Academy of Fine Arts -Schools of Architecture, Design and Conservation (KADK), Philip de Langes Allé 10, Copenhagen 1435, København, Denmark

e-mail: imil@kadk.dk

A. Iversen

Sustainability and Landscape Design, Henning Larsen Architects, Copenhagen, Denmark

W. Imms and T. Kvan (eds.), Teacher Transition into Innovative Learning Environments, https://doi.org/10.1007/978-981-15-7497-9_17 
activities. A better understanding of the relationship between indoor lighting conditions and human (learning-related) behaviour equips us to design more suitable learning environments.

Our research, embedded in the architectural practice Henning Larsen, explores this relationship specifically in public primary schools in Denmark, where recently a major educational reform took place (The Danish Ministry of Education, 2014). Greater emphasis is now put on stimulating "learning" through: physical playfulness, diversity in curricular activities, and addressing individual learning styles instead of applying a generalized approach. As a result, Danish primary schools have implemented a teaching philosophy that promotes individuality, flexibility and diversity.

Ideally, the design of spaces where this "new" learning takes place facilitates these educational principles. This environmental need has also been recognized by the Danish local governments, and a significant number of primary schools have been or are currently in the process of being renewed or refurbished. In line with this development, our research ambition became to explore how artificial lighting can play an active role in creating such supportive "new" learning environments, and simultaneously grow our knowledge on how artificial lighting influences (learningrelated) behaviour of pupils in Danish primary schools.

\section{The Influence of Artificial Light}

Previous researchers studying the influence of artificial light on users of learning environments found that certain characteristics impact their visual and cognitive capabilities, biological clock, mood, motivation, and/or (social) behaviour-ultimately affecting (academic) performance. Most evident are characteristics of "light" such as intensity, colour temperature and combinations thereof (Sleegers et al., 2012; Mott et al., 2012; Wessolowski et al., 2014), as well as "system" characteristics such as glare, flicker, and control (Winterbottom \& Wilkins, 2009). Yet little studied, but possibly equally influential are "spatial" characteristics of artificial light, which co-define the appearance of (Boyce, 2014) and consequently the perceived atmosphere in (Vogels, 2008) a space. One of these is spatial contrast, which is the result of how (artificial) light is distributed in a space, creating a pattern of relative light and darkness. A pattern with great variation is considered high-contrasting or nonuniform-also referred to as "dramatic", whereas a pattern with little variation is considered low-contrasting or uniform-also referred to as "plain" (Flynn et al., 1973, 1977, 1979; Govén et al., 2011; Boyce, 2014).

The main difference between light- and system characteristics, and spatial contrast is that these first two are product variables, defined by the technical characteristics of the lighting installation fitted. Whereas spatial contrast is a design variable, meaning that it is tailored by the architect to fabricate the intended spatial experience (Boyce, 2014), and herewith a perceived atmosphere (Vogels, 2008). As our research 
is embedded in architectural design practice with a strong emphasis on optimizing the spatial experience in our built environments, exploring the influence of spatial contrast in learning environments became the theme to investigate further.

\section{The Architect's Responsibility}

Arguably, architects should treat artificial light with similar importance as they do for natural light, which is commonly considered a significant design criterion, to guarantee a healthy and stimulating indoor learning climate. It seems well recognized that daylight, when utilized wisely, can improve our wellbeing, indoor experience and academic performance (Gifford, 2007). For instance, one frequently referenced study verified that allowing the right amount of daylight indoors helps students to learn faster and achieve better results (Heschong Mahone Group, 2003; World Green Building Council, 2013). In addition to attending to its quantitative values, daylight is also considered a rich qualitative resource, in particular when it comes to designing a dynamic learning environment with variations of intensities, colour, orientation and movement of natural light through a space. Such variations have been found to influence our spatial experience over time, and thereby to increase motivation and our ability to learn and be creative (Jensen et al., 2012).

Nonetheless, the availability of natural light in interior spaces will vary depending on location, orientation, time of day and season, and artificial light is often required to complement or supplement inadequacies. As a consequence, artificial light has significant influence on our spatial experience and should likewise be a design criterion on the architect's agenda. However, when interviewing numerous Danish educational architects about their (artificial light) design practice, it became apparent that it is not (yet) considered attending to beyond meeting the basic illumination requirements in the national building regulations. These merely safeguard that the "average user" is able to comfortably move, read and write by prescribing a maintained average illumination and uniformity level for all hours of use. With this in mind, we explored the consequences of this approach for the indoor lighting conditions in contemporary learning spaces.

\section{Artificial Light in Today's Learning Spaces}

Field studies in eight Danish primary schools (of which four examples are shown in Fig. 1a-d) revealed the common application of "one-type-fits-all" ceiling-based artificial lighting systems, resulting in a relatively uniform, or low contrast, distribution of light. The consequential spatial appearance, or perceived spatial atmosphere, was often described as "functional", but "dull", "uninspiring", or even "hospital-like", i.e. unpleasant. When discussing how these systems are used during teaching hours, educators' responses did not go much beyond: “... switching it ON at the start of day, 


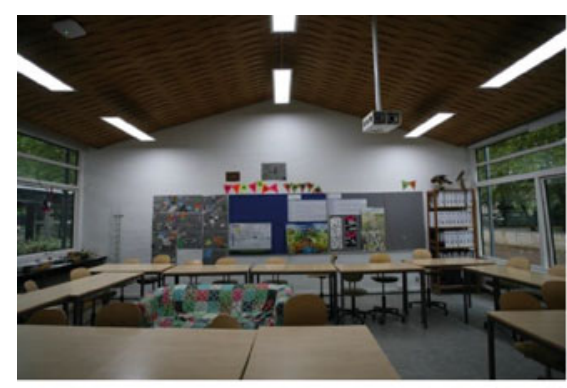

a. Lyngby Skole

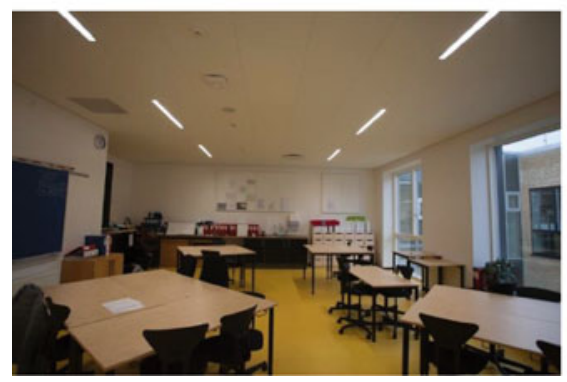

c. Sophia Skole

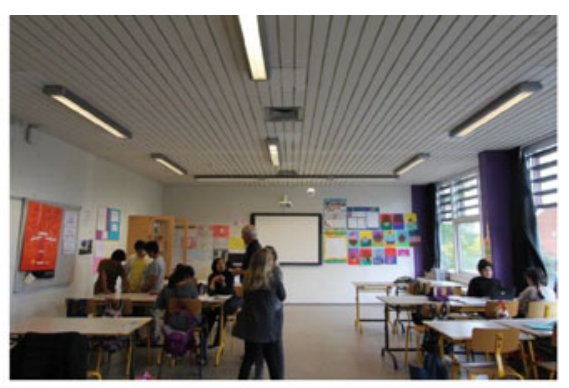

b. Albertslund Skole

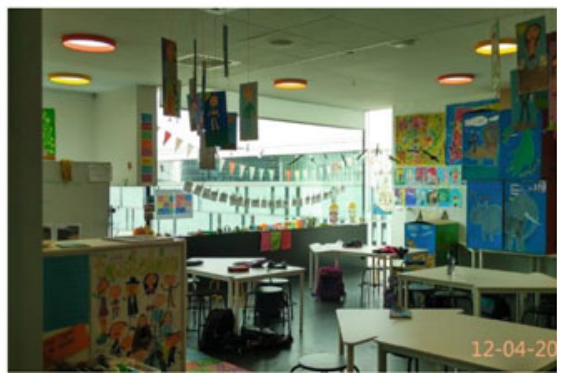

d. Ørestad Skole

Fig. 1 Impressions of artificial lighting conditions in primary Danish learning spaces

and OFF at the end". But when asked to elaborate on their experience with and/or use of light in general while teaching, several went on to describe how they did use it in some form. In most examples, their intention is to create (in their words) the "right" atmosphere to promote behaviour and mood that benefits pupils' ability to concentrate. Some did so by deliberately increasing or decreasing the light levels based on the type of curricular activity at hand. Others used their own sources of light such as candles or simple plug-in table luminaires to promote local focus and quietness, or to cluster pupils' attention in small groups. These and other examples revealed that a number of educators sought to create a particular atmosphere intended to foster focus and concentration among pupils when deemed valuable (e.g. certain curricular activities).

\section{Atmosphere to Concentrate}

Previous research has revealed that deliberate design with light and darkness codefines the appearance of a space (Boyce, 2014), which contributes to our experience of atmosphere (Vogels, 2008). This is, among others, shaped by the way light is distributed in a space, or spatial contrast, as described above. Our field studies in eight primary learning environments revealed that a low-contrast, or uniform, distribution 
of artificial light has become widespread. The resulting luminous atmosphere is described as functional, though uninspiring and dull. The educators who try to modify this atmosphere by using local light sources instead of the generic ceiling lighting to promote focus and concentration are effectively changing the manifestation of spatial contrast in their environment.

These findings suggest that spatial contrast has the potency to be an instrument for educators to orchestrate a different-then-normal atmosphere in their learning environment, and in their view, aid concentration during certain curricular activities. If this idea could be demonstrated to be true, then artificial lighting might receive greater attention in learning space design. It was therefore further explored in a design context by hosting workshops with a number of architects at Henning Larsen, which led to the formulation of the following hypothesis:

Focussed, local light leads to high-spatial contrast that co-constructs an atmosphere that promotes pupil behaviour and mood states benefitting their ability to concentrate

These workshops also informed the design of an artificial lighting prototype capable of creating the wished for high-spatial contrast by educators on-demand.

\section{The "Living Lab"}

To validate this hypothesis, this prototype has been implemented in four learning spaces of Frederiksbjerg folkeskole (Fig. 2), a new public school located in Aarhus (DK). This school, inaugurated in August 2016 and co-designed by Henning Larsen, is considered: "a benchmark example of the new educational ideals translated into supportive learning environments" (Norhcon, 2016), and was therefore thought to be a credible example to evaluate our hypothesis in the context of the new reform.

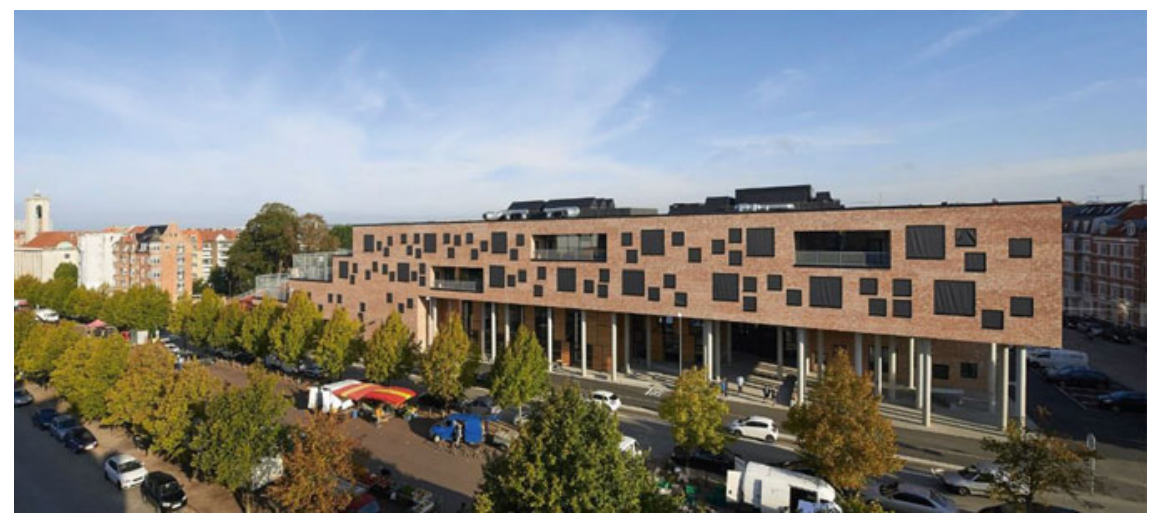

Fig. 2 Impression of the new Frederiksbjerg Skole in Aarhus (DK). Photo and image credits: Henning Larsen, (c) Hufton+Crow 
The four spaces selected are located in close proximity and have relatively similar natural light and spatial layout characteristics. Two spaces are used each by one group of 1st to 3rd grade pupils (aged 6-8 years) and host a varied palette of curricular activities. The other two spaces are used by eight rotating groups of 4th to 6th grade pupils (aged 9-12 years) for 90-minute mathematics lessons. Both demographic and curricular settings were thought to benefit from improved pupil concentration.

The "prototype design" has been implement in addition to the existing "default design" in these four spaces. The default lighting design consist out of six evenly spread ceiling luminaires. Users may choose to either switch all six luminaires: OFF (option A, Fig. 3a, b) or ON (option B, Fig. 4a, b) —with an option to increase or decrease the overall light level. The default ON state causes a low-contrast distribution of light and complies with current Danish building regulations to provide for an average "working area" illumination level of $300 \mathrm{~lx}$ with a uniformity ratio of 0.6 during all hours of use. The prototype lighting design consists out of the default system complemented by six additional suspended pendants above typical work surfaces (aka working desks) permitting for local, focussed light at eye-level. Users may choose to switch all lighting OFF (option A, Fig. 3a, b), or to activate

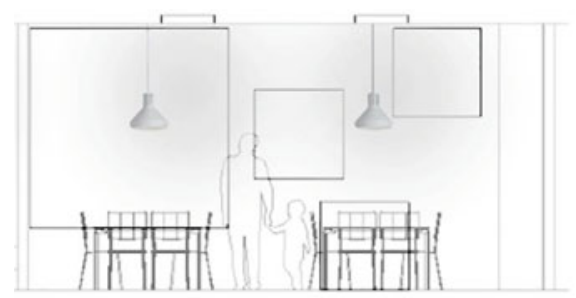

a Option A (all luminaires $O F F$ )

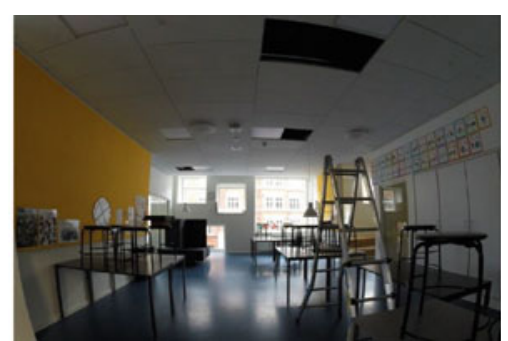

b Option A (all lighting $O F F$ )

Fig. 3 Option A - No artificial lighting activated - daylight only. a Sketch depicting artificial lighting Option A. b Photo of the classroom with artificial lighting Option A activated. Image credits: Henning Larsen, Imke Wies van Mil. Photo credits: Henning Larsen, Halfdan Trolle

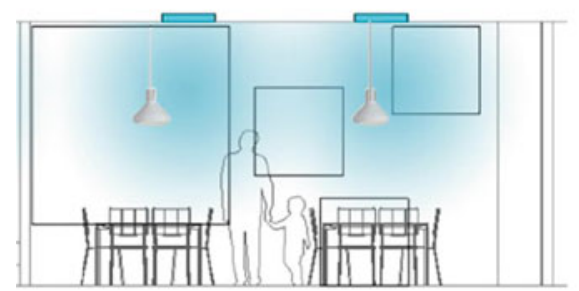

a Option B (ceiling lighting $O N$ )

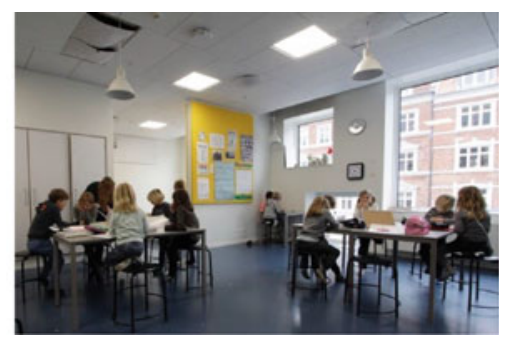

b Option B(ceiling lighting ON)

Fig. 4 Option B - Ceiling lighting activated. a Sketch depicting artificial lighting Option B. b Photo of the classroom with artificial lighting Option B activated. Image credits: Henning Larsen, Imke Wies van Mil. Photo credits: Henning Larsen, Halfdan Trolle 


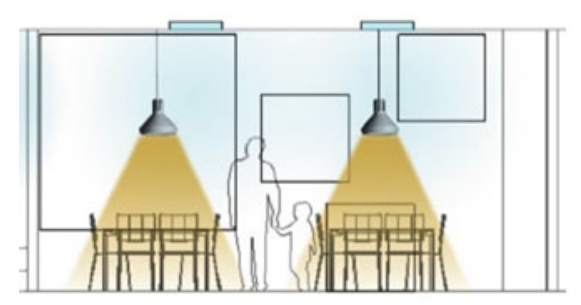

a Option C (ceiling + pendants $O N)$

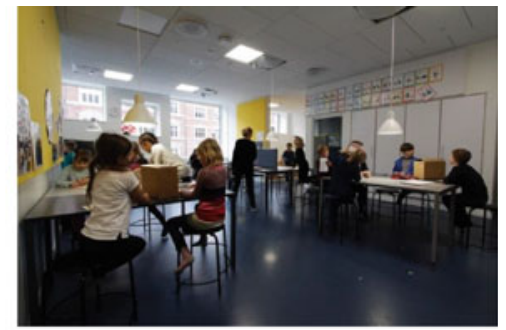

b Option C (ceiling+pendant $O N)$

Fig. 5 Option C - Ceiling and pendant lighting activated. a Sketch depicting artificial lighting Option C. b Photo of the classroom with artificial lighting Option C activated. Image credits: Henning Larsen, Imke Wies van Mil. Photo credits: Henning Larsen, Halfdan Trolle

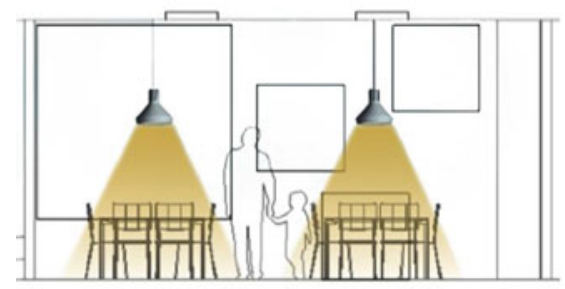

a Option D (pendant lighting ON)

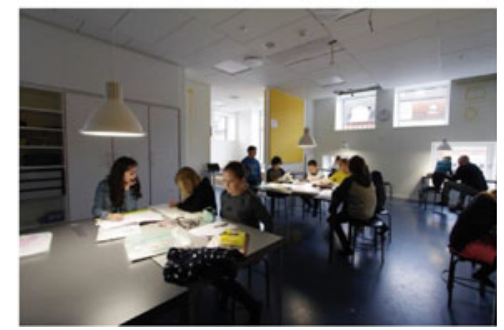

b Option D (pendant lighting ON)

Fig. 6 Option A - Pendant lighting activated. a Sketch depicting artificial lighting Option D. b Photo of the classroom with artificial lighting Option D activated. Image credits: Henning Larsen, Imke Wies van Mil. Photo credits: Henning Larsen, Halfdan Trolle

the default ceiling lighting only (option B, Fig. 4a, b) which results in a low-contrast distribution of light. They may also choose to activate both the default and new pendant system simultaneously (option C, Fig. 5a, b), or the pendant system only (option D, Fig. 6a, b). Both results in high or very high-contrast distributions of light.

To evaluate the validity of our hypothesis, the influence of the high-contrast prototype lighting design on pupil behaviour and their mood, was compared to that presented under influence of the low-contrast default lighting design.

\section{Data Collection}

To evaluate whether the prototype design effected pupil concentration, we looked at two specific behavioural pupil actions: their noise levels and their physical activity during a curricular session. A correlation is thought to exist between the level of noise pupils are exposed to (including their own noise), and their ability to concentrate (Klatte et al., 2013). Similarly, this is the case for physical activity, specifically 
the length of time seated at one place. It is anticipated that for our hypothesis to be considered valid, the prototype design should lead to lower average student noise and longer average time seated at the working place. In addition, we also assessed variances in pupil's responses towards their learning environment, anticipating greater satisfaction to positively influence mood and motivation. To exclude as many intervening variables as possible, a range of other (environmental) factors have been measured as well.

A mixed-method approach was applied to collect the described quantitative and qualitative data. This included anthropological techniques such as non-participant in classroom observations, semi-structured interviews and focus groups with educators and pupils, as well as continuous measurements of the indoor climate variables, and recordings of the lighting system usage. Noise levels were recorded with soundlevel meters, and physical activity by observations and video documentation. Data collection took place during the months of February, March and April of 2017. In each of the four learning spaces, the pupils and their educators experienced the two lighting designs in succession for three continuous weeks. Two of the spaces (one lower, one mid-level) used the default lighting design during the first three-week interval, and the prototype lighting design during the following three weeks. The other two rooms experienced both situations in opposite order. The weekly schedule of curricular activities in each space, as well as their furniture and spatial layouts were kept consistent during the entire research period.

\section{Preliminary Findings}

Currently we are in the process of analysing our data. We recognise we are working in a specific cultural context of education and use of light. Preliminary findings, however, indicate support for our hypothesis that high spatial contrast, created by focussed, local light distribution, lowers average pupil noise. An initial analysis of the sound data collected indicates that during activation of the local pendant lighting, the average noise level in these rooms decreased up to $10 \%$, which is deemed significant. In addition, a positive increase in environmental satisfaction by both educators and pupils was found, and educators preceived (but could not document) longer periods of concentration among pupils. Further analysis of video recordings and observational notes is required.

The immediate outcome is however that Frederiksbjerg skole requested for the prototype lighting scenario to be made into a permanent installation (Fig. 7), and to be replicated in other spaces too. Not only is this a successful conclusion for our design-led research approach, the installation also allows for a longer period of study during Autumn 2017, contributing data for further analysis. Furthermore, additional pupil exercises, both quantitative and qualitative in nature, will be added to our data set. Analysis of these exercises may indicate more accurately what the impact of the new lighting scenario is on the ability of students to concentrate. 


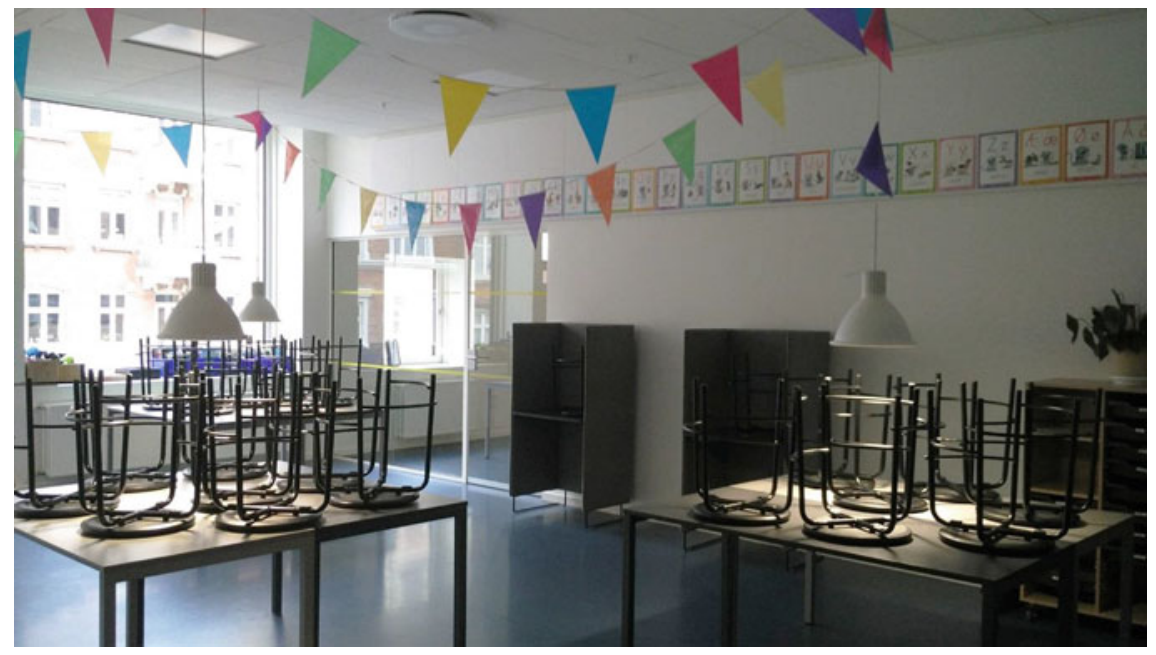

Fig. 7 Permanent lighting installation inaugurated by the pupils and educator. Photo credits: Henning Larsen, Imke Wies van Mil

If further data analysis backs up our initial findings described above, we might may conclude that current buildings regulations do not promote the most favourable luminous learning environments in Denmark and changes should be considered.

Acknowledgements This research is financially supported by Innovationfonden Denmark and Elforsk (Dansk Energi), and is executed in collaboration with Henning Larsen, The Danish Royal Academy of Fine Arts, Frederiksbjerg Skole, Aarhus Kommune, the Technical University of Denmark, Aarhus University and Fagerhult Belysning AB. Data utilised in this research was obtained in adherence to the required ethical protocol of the author's host institution. All images and diagrams are the property of the author, or the author has obtained consent to use them from the appropriate copyright owner.

\section{References}

Barrett, P., Zhang, Y., Davies, F., \& Barrett, L. (2015). Clever rooms-Summary report of the HEAD Project. University of Salford, Manchester. ISBN 978-1907842634.

Boyce, P. R. (2014). Human factors in lighting. 3rd edition. CRC Press. Boca Raton, Florida. ISBN 978-1439874882.

Boyce, P. R. (2014b). Editorial: Light distribution-a missing variable. Lighting Research and Technology, 46, 617. https://doi.org/10.1177/1477153514556940.

Flynn, J. E., Spencer, T. J., Martyniuk, O., Hendrick, C. (1973). Interim study of procedures for investigating the effect of light on impression and behavior. Journal IES-Transaction, 87-94. http://media.ies.org/docs/research/100papers/040.pdf.

Flynn, J. E. (1977). A study of subjective responses to low energy and non-uniform lighting systems. Journal IES Lighting Design + Application, 7, 167-179. 
Flynn, J. E., Hendrick, C., Spencer, T. J., Martyniuk, O. (1979). A guide to methodology procedures for measuring subjective impressions in lighting. Journal IES Lighting Design + Application, 8 , 95-110. http://media.ies.org/docs/research/100papers/041.pdf.

Gifford, R. (2007). Environmental psychology-Principles and practice. 4th edition. Optimal Books. ISBN 978-0968854310.

Govén, T., Laike, T., Raynham, P., \& Sansal, E. (2011). Influence of ambient light on the performance, mood, endocrine systems and other factors of school children. The CIE 27th Session. South Africa: Sun City.

Heschong Mahone Group - California energy commission (2003). Windows and rooms: A study of student performance and the indoor environment. Technical Report. http://www.energy.ca.gov/ 2003publications/CEC-500-2003-082/CEC-500-2003-082-A-08.PDF.

Jensen, J. L., Schjødt-Pedersen, M., Houlberg Abildhauge Olesen, M., Brandt Østerby, A., Rebsdorf Rostved, M., \& Henning Larsen Architects. (2012). Learning spaces: Interviews about and case studies of learning environments of tomorrow. Retrieved from https://issuu.com/henninglarsenar chitects/docs/learning_spaces_en_web_red.

Klatte, M., Bergström, K., \& Lachmann, T. (2013). Does noise affect learning? A short review on noise effects on cognitive performance in children. Frontiers in Psychology; 4, 578. https://doi. org/10.3389/fpsyg.2013.00578.

Mott, M., Robinson, D. H., Walden, A., Burnette, J., \& Rutherford, A. S. (2012). Illuminating the effects of dynamic lighting on pupil learning. SAGE Open. https://doi.org/10.1177/215824401 2445585 .

Norhcon. (2016). Årets skolebyggeri. https://nohrcon.dk/information/aarets-skolebyggeri-2016-fre deriksbjerg-skole-i-aarhus/.

Sleegers, P. J. C., Moolenaar, N. M., Galetzka, M., Pruyn, A., Sarroukh, B. E., \& Van der Zande, B. (2012). Lighting affects pupils' concentration positively: Findings from three Dutch studies. Lighting Research and Technology, 45, 159-175. https://doi.org/10.1177/1477153512446099.

The Danish Ministry of Education. (2014). Improving the public school-Overview of reform of standards in the Danish public school (primary and lower secondary education). http://www.une sco.org/education/edurights/media/docs/10354f6c8699be7af856353a08a0e2681f957cfa.pdf.

Vogels, I. (2008). Atmosphere metrics-Development of a tool to quantify experienced atmosphere. In: J. Westerink, M. Ouwerkerk, T. J. M. Overbeek, W. PasveerF. Pasveer (Eds.) Probing experience-From assessment of user emotions and behaviour to development of products. Philips Research Book Series, Volume 8. Springer Science \& Business Media, pp. 25-41.

Wessolowski, N., Koenig, H., Schulte-Markwort, M., \& Barkmann, C. (2014). The effect of variable light on the fidgetiness and social behavior or pupils in school. Journal of Environmental Psychology, 39, 101-108. https://doi.org/10.1016/j.jenvp.2014.05.001.

Winterbottom, M., \& Wilkins, A. (2009). Lighting and discomfort in the room. Journal of Environmental Psychology, 29, 63-75. https://doi.org/10.1016/j.jenvp.2008.11.007.

World Green Building Council (2013). The business case for green building: A review of the costs and benefits for developers, investors and occupants. Technical Report. http://www.worldgbc. org/sites/default/files/Business_Case_For_Green_Building_Report_WEB_2013-04-11-2.pdf.

Imke Wies van Mil (Denmark) is a lighting designer and researcher. She currently works at Henning Larsen Architects (Copenhagen, DK) where she contributes to their in-house lighting design expertise on a diverse range of architectural projects. In collaboration with the Royal Danish Academy of Fine Arts, Imke is simultaneously working towards a Ph.D. degree where her interest goes out to improve artificial lighting conditions in educational environments. She does so by conducting her research both in the academic and practice field. In both her roles, Imke advocates a knowledge-based approach towards architectural lighting design. Before taking up her current positions, Imke worked for several years as a lighting designer for Arup Lighting, both in Amsterdam (NL) and London (UK). She holds a M.Sc. degree in Industrial Product Design from Delft University of Technology (2005), and MSc degree in Lighting Design (with distinction) from the Bartlett, University College London (2009). 
Open Access This chapter is licensed under the terms of the Creative Commons Attribution 4.0 International License (http://creativecommons.org/licenses/by/4.0/), which permits use, sharing, adaptation, distribution and reproduction in any medium or format, as long as you give appropriate credit to the original author(s) and the source, provide a link to the Creative Commons license and indicate if changes were made.

The images or other third party material in this chapter are included in the chapter's Creative Commons license, unless indicated otherwise in a credit line to the material. If material is not included in the chapter's Creative Commons license and your intended use is not permitted by statutory regulation or exceeds the permitted use, you will need to obtain permission directly from the copyright holder.

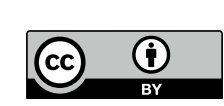

